\title{
Anticancer Effect of Nitric Oxide on Human Lymphoma Cells
}

\author{
Junko Tanaka, Kunio Koshimura, Yoshio Murakami, Michihiro Tsumori and Yuzuru Kato \\ First Division, Department of Medicine, Shimane Medical University, Izumo, Japan.
}

\begin{abstract}
We examined cytocidal effects of nitric oxide (NO) on cultured lymphoma and myeloma cells isolated from three patients and one patient, respectively. In one case with lymphoma, sodium nitroprusside (SNP) dose-relatedly decreased viable cell number as anticancer drugs. After chemotherapy, SNP remained effective but anticancer drugs were ineffective. SNP had no effect on number of viable normal lymphocytes from lymphoma patients. SNP was effective but anticancer drugs were ineffective in one lymphoma case and only anticancer drugs were effective in one case. In myeloma patient, SNP had little effect. These results suggest that some lymphoma cells are sensitive to NO.
\end{abstract}

Nitric oxide (NO) is a multifunctional molecule and produced in a variety of mammalian cells. At physiological levels, NO is associated with neurotransmission and vasodilatation. At higher levels, NO has tumoricidal and bacteriocidal effects $(8$, $10)$. In the cell-mediated immune responses, NO is produced in macrophages, neutrophils and lymphocytes $(1,3,4)$. Several lines of evidence indicate that NO has cytotoxic effects on human cell line of leukemia and lymphoma $(2,4,5,6,7)$. These results raise the possibility that a NO donor is a chemotherapeutic agent for hematological disorders. It is reported that NO is effective on freshly isolated human leukemia cells (11). However, the effects of NO on freshly isolated human lymphoma cells remain to be elucidated. In the present study, we investigated the possibility of $\mathrm{NO}$ as a novel agent for the treatment of hematological malignancy using

Address for correspondence and reprint requests to Dr K. Koshimura, M. D., at above address.

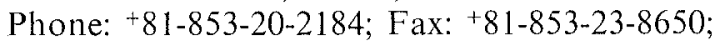

E-mail: kunio@shimane-med. ac.jp

Abbreviations used: CAB, carboplatin; CPA, cyclophosphamide; MIT, mitoxantron; NO, nitric oxide; SNP, sodium nitroprusside; VCR, vincristine. lymphoma and myeloma cells freshly isolated from patients.

Patients. Lymphoma cells were obtained from 3 patients (Patient A, B and C) with malignant lymphoma and myeloma cells were obtained from one patient (Patient D) with multiple myeloma who were hospitalized at the First Division, Department of Medicine, Shimane Medical University Hospital. Patient A was 80 year old male with diffuse $B$ cell type malignant lymphoma. The positive surface markers for lymphoma cells were CD7, CD10, CD19, CD20, CD22 and CD33. Patient B was 84 year old male with diffuse B cell type malignant lymphoma. The positive surface markers for lymphoma cells were CD19, CD20, CD21, CD23, CD38, CD57, HLA-DR, SM-IgG and SM-IgM. Patient $C$ was 74 year old female with diffused mixed $B$ cell type malignant lymphoma. The positive surface markers for lymphoma cells were CD19, CD20, CD21, CD22 and HLA-DR. Patient D was 69 year old female with $\mathrm{IgG}-\boldsymbol{x}$ type multiple myeloma. Lymphoma cells of Patient A and B were collected from ascites and those of Patient $\mathrm{C}$ were from peripheral venous blood and myeloma cells of Patient $D$ were collected from bone marrow. Peripheral lymphocytes were collected from Patient $\mathrm{A}$ and a healthy volunteer. Lymphoma cells were collected 
from Patient A both before and after the chemotherapy. From Patient B, C and D, cells were collected only before their therapy. Flow cytometry and microscopic examination revealed that more than $90 \%$ of the collected cells of Patient A, B and D and more than $60 \%$ of the collected cells of Patient $\mathrm{C}$ were malignant cells. Cell culture. Collected cells were diluted with saline and centrifuged at 2,500 rpm for $10 \mathrm{~min}$. The pellet was resuspended in saline and $3-5 \mathrm{~mL}$ of the suspension was layered on $5 \mathrm{~mL}$ of Histopaque-1077 (Sigma, St. Louis, MO, U.S.A.). After centrifugation at $1,500 \mathrm{rpm}$ for $15 \mathrm{~min}$, the opaque interface containing the cells were washed with saline twice and plated in 96-well culture dish (ICN Biomedicals, Aurora, OH, U.S.A.) (2$\left.4 \times 10^{6} / \mathrm{mL}\right)$. The cells were cultured in RPMI 1640 (Sigma, Irvine, U. K.) supplemented with $10 \%$ fetal calf serum (FCS) for 3-5 days before experiments.

Experiment for sensitivity to test drugs. The cells were added with anticancer drugs used for the therapy or sodium nitroprusside (SNP) every $24 \mathrm{~h}$ and cultured for 5 days. At the end of the culture, viable cell number was measured with MTT assay as described previously (12).

Statistical analysis. All results were expressed by means \pm SEM. The significance of difference was tested with ANOVA and Fisher's test. A probability level of $P<0.05$ was considered statistically significant.

The lymphoma cells of Patient A were sensitive to cyclophosphamide (CPA) and vincristine (VCR) before the therapy but the lymphoma cells became insensitive to these anticancer drugs after the treatment with these drugs (Fig. 1A), suggesting that the cells obtain resistance to these drugs during the chemotherapy. In contrast, sodium nitroprusside (SNP) was sensitive to the lymphoma cells both before and after the therapy although SNP reduced its potency after the therapy (Fig. 1B), suggesting that SNP was effective on lymphoma cells independently of the insensitiveness of the anticancer drugs to the lymphoma cells. Peripheral lymphocytes of Patient A were resistant to anticancer drugs and SNP as observed in a healthy volunteer (Fig. 1C). Thus, both anticancer drugs and SNP are considered to have cytotoxic effects only on lymphoma cells. In Patient B, lymphoma cells were sensitive only to carboplatin (CAB) and mitoxantron (MIT) but not VP 16, while the lymphoma cells were sensitive to SNP as potent as CAB and MIT
(Fig. 2A). In contrast, the lymphoma cells of Patient $C$ were sensitive to $\mathrm{CAB}$ but not to SNP (Fig. 2B). The myeloma cells of Patient $\mathrm{D}$ were weakly sensitive to CPA and SNP (Fig. 2C).

Taking account for laboratory data, the cell type of SNP-effective lymphoma (Patient A and $B$ ) was diffuse $B$ cell type and that of non-effective case (Patient C) was mixed B cell type. It is reported that $\mathrm{CD} 23$ is associated with proliferation of acute myelogenous leukemia cells (9). However, there was no surface marker possibly associated with SNP sensitivity. SNP had little effect on myeloma cells of Patient D. However, it cannot be concluded that SNP is not effective on myeloma cells. Although we examined small number of cases, it is assumed that SNP has an anticancer effect on some lymphoma cells as potent as anticancer drugs.

The culture system of freshly isolated human cells introduced in our laboratory gave us various useful information concerning chemotherapy for patients such as drug potency and drug resistance. Using this system, we are now attempting to design the chemotherapy protocol and to monitor drug sensitivity in addition to the trial of a $\mathrm{NO}$ donor for hematological disorders.

This work was supported in part by grants from the Ministry of Education and Culture, Japan, the Ministry of Health and Welfare, Japan, and the Shimane Institute for Intractable Diseases. We thank to Mrs A. Kanayama for her technical assistance and Mrs A. Kawakami for her secretarial help.

Received 15 December 1998; and accepted 30 December 1998.

\section{REFERENCES}

1. Brüne B., Götz C., Mebmer U. K., Sandau K., Hirvonen M. -R. and LApEtinA, E. G. (1997) Superoxide formation and macrophage resistance to nitric oxide-mediated apoptosis. J. Biol. Chem. 272, 7253-7258.

2. Dugas N., Mossalay 1 M. D., Calenda A., Léotard A., Bécherel P., Mentz F., Ouaaz F., Arock M., Debré P., Dornand J. and Dugas B. (1996) Role of nitric oxide in the anti-tumoral effect of retinoic acid and 1, 25dihydroxyvitamine $\mathrm{D}_{3}$ on human promonocytic leukemic cells. Blood 88, 3528-3534.

3. Evans T. J., Buttery L. D. K., Carpenter A., Springall D. R., Polak J. M. and Cohen J. (1996) Cytokine-treated human neutrophils contain inducible nitric oxide synthase that produces nitration of ingested bacteria. Proc. Natl. Acad. Sci. USA 93, 9553-9558.

4. Filep J. G., Baron C., Lachance S., Perreault C. and CHAN J. S. D. (1996) Involvement of nitric oxide in targetcell lysis and DNA fragmentation induced by murine 

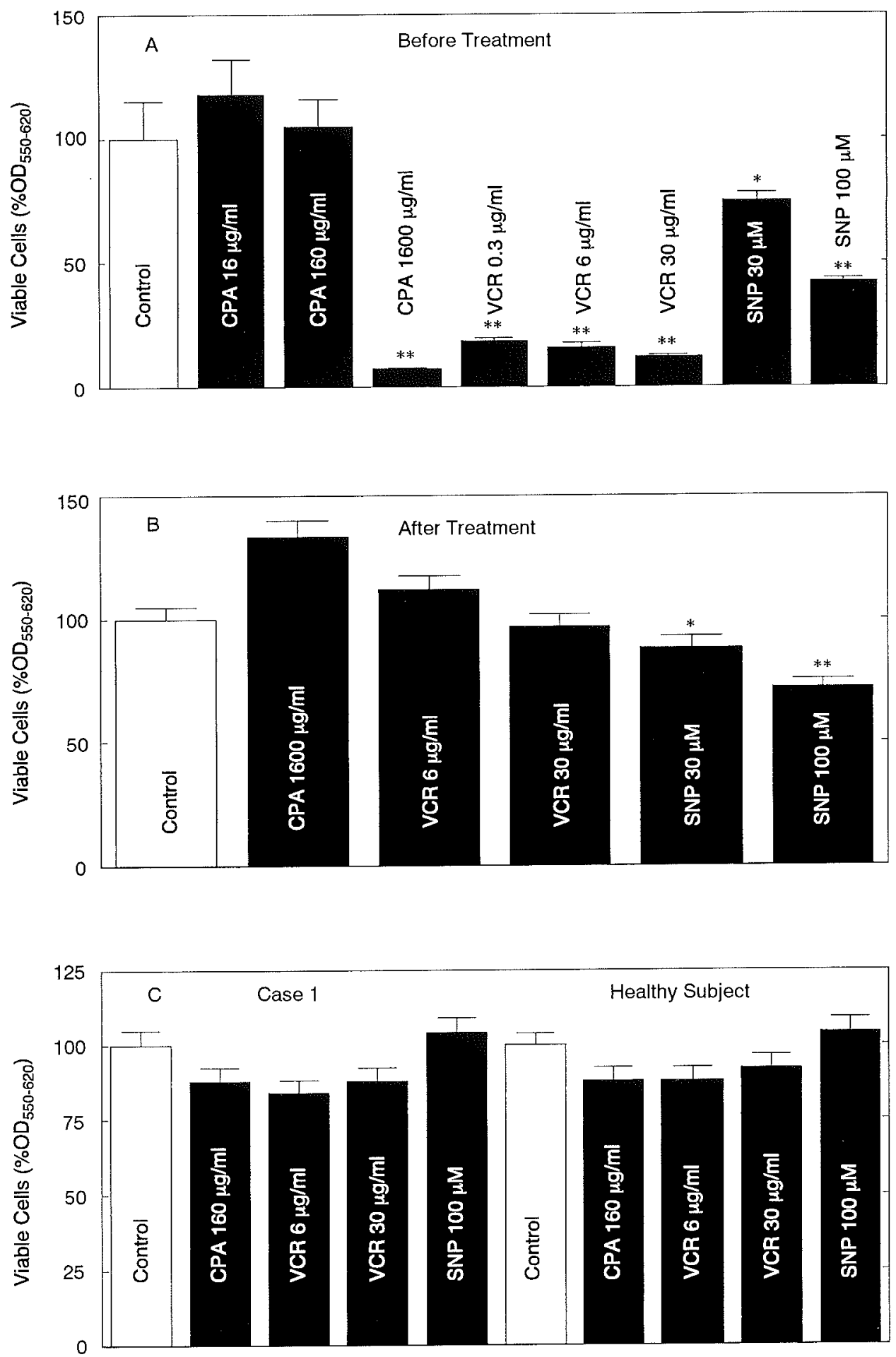

Fig. 1 Effects of anticancer drugs and sodium nitroprusside on lymphoma cells and peripheral lymphocytes of Patient A. A: Effects of anticancer drugs on lymphoma cells before and after chemotherapy. B: Effects of sodium nitroprusside on lymphoma cells before and after chemotherapy. C: Effects of anticancer drugs and sodium nitroprusside on peripheral lymphocytes of Patient $A$ and normal volunteer. Each value is mean \pm SEM of ten determinations.

$*, P<0.05, * *, P<0.01$ vs, the corresponding control group. CPA, cyclophosphamide; VCR, vincristine; SNP, sodium nitroprusside. 

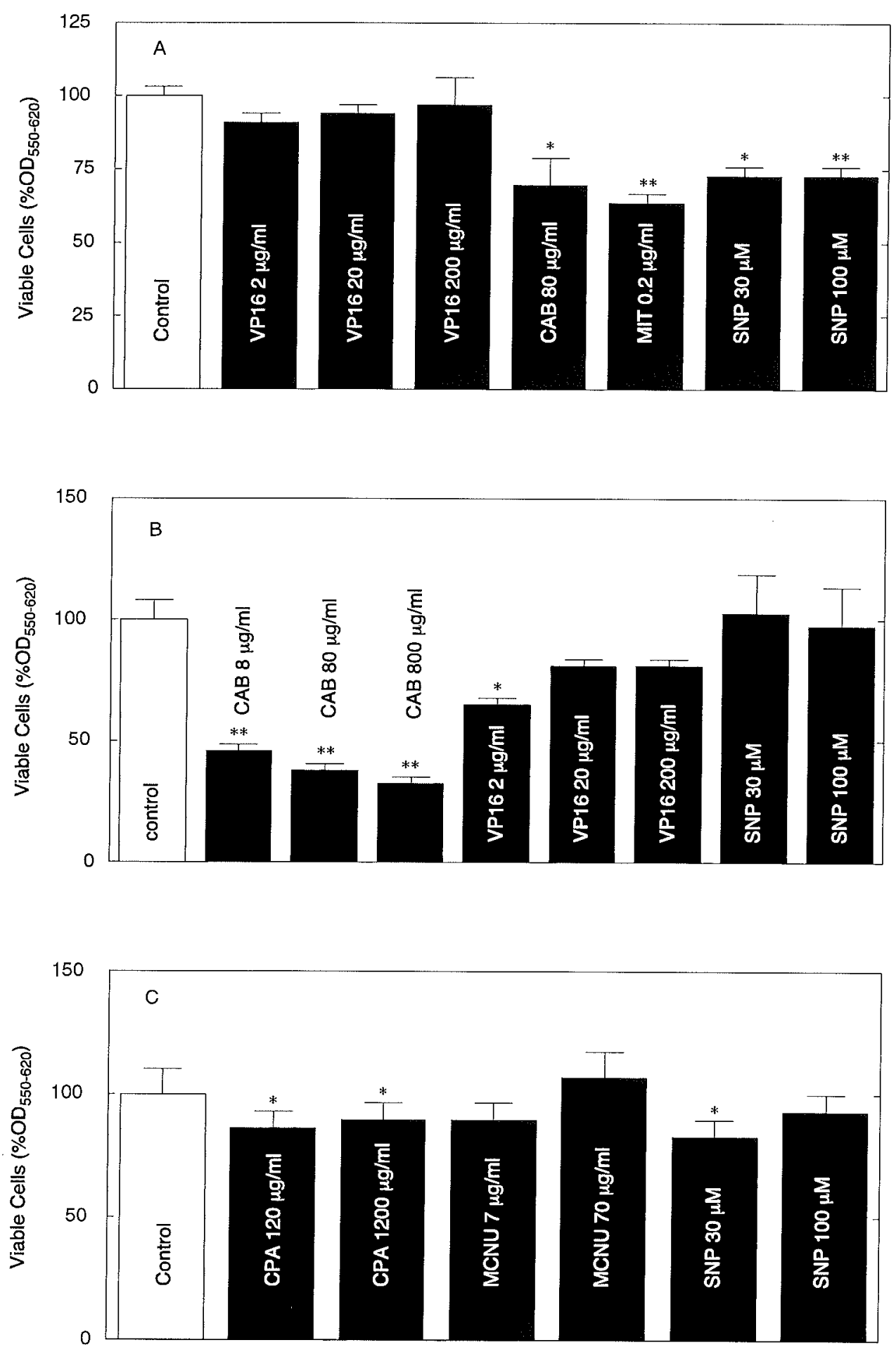

Fig. 2 Effects of anticancer drugs and sodium nitroprusside on lymphoma and myeloma cells. A: Effects of drugs on lymphoma cells of Patient B. B: Effects of drugs on lymphoma cells of Patient C. C: Effects of drugs on myeloma cells of Patient $\mathrm{D}$. Each value is mean $\pm \mathrm{SEM}$ of ten determinations. $*, P<0.05, * *, P<0.01$ $v$ s. the corresponding control group. CAB, carboplatin; MIT, mitoxantron. 
natural killer cells. Blood 87, 5136-5143.

5. Jiang H., Stewart C. A., Fast D. J. and Leu R. W. (1992) Tumor target-derived soluble factor synergizes with IFN- $\gamma$ and IL-2 to activate macrophages for tumor necrosis factor and nitric oxide production to mediate cytotoxicity of the same target. J. Immunol 149, 2137-2146.

6. Kwon N. S., Stuehr D. J. and Nathan C. F. (1991) Inhibition of tumor cell ribonucleotide reductase by macrophage-derived nitric oxide. J. Exp. Med. 174, 761767.

7. Magrinat G., Mason S. N., Shami P. J. and Weinberg J. B. (1992) Nitric oxide modulation of human leukemia cell differentiation and gene expression. Blood 80, 1880-1884.

8. McCall T. and Vallance P. (1992) Nitric oxide takes centre-stage with newly defined roles. Trends Phamacol. Sci. 13, 1-6.

9. Ouaaz F., Sola B., Issaly F., Kolb J. P., Davi F., Mentz
F., Arock M., Paul-Eugène N., Körner M., Dugas B., Debré P. and Mossalay M. D. (1994) Growth arrest and terminal differentiation of leukemic myelomonocytic cells induced through ligation of surface CD23 antigen. Blood 84, 3095-3104.

10. SChmidt H. H. H. W. and Walter U. (1994). NO at work. Cell 78, 919-925.

11. Shami P. J., Moore J. O., Gockerman J. P., Hathorn J. W., Misukonis M. A. and Weinberg J. B. (1995) Nitric oxide modulation of the growth and differentiation of freshly isolated acute non-lymphocytic leukemia cells. Leukemia Res. 19, 527-733.

12. Tanaka J., Koshimura K., Murakami Y., Sohmiya M., Yanalhara N. and Kato Y. (1997) Neuronal protection from apoptosis by pituitary adenylate cyclase activating polypeptide. Regul. Pept. 72, 1-8. 